will take any account of the arguments put forward - but at least the issues have been aired. Our suggestions were intended to provoke discussion, in the hope that we might make a little progress towards a still distant goal.

1 Löwe B, Spitzer RL, Williams JBW, Mussell M, Schellberg D, Kroenke K. Depression, anxiety and somatization in primary care: syndrome overlap and functional impairment. Gen Hosp Psychiatry 2008; 30: 191-9.

2 Goldberg DP, Krueger RF, Andrews G, Hobbs M. Emotional disorders: cluster 4 of the proposed meta-structure for DSM-V and ICD-11. Psychol Med 2009; 39: 2043-59.

3 Andrews G, Goldberg DP, Krueger RF, Carpenter WT, Hyman SE, Sachdev P, et al. Exploring the feasibility of a meta-structure for DSM-V and ICD-11: could it improve utility and validity? Psychol Med 2009; 39: 1993-2000

4 Goldberg DP, Andrews G, Hobbs MJ. Where should bipolar disorder appear in the meta-structure? Psychol Med 2009; 39: 2071-81.

David Goldberg, Institute of Psychiatry, King's College London, UK.

Email: David.Goldberg@iop.kcl.ac.uk

doi: 10.1192/bjp.197.2.158a

\section{Suffrage or suffering? Voting rights for psychiatric in-patients}

Before the Representation of the People Act 1949, in-patients in psychiatric settings were usually denied the right to vote in the UK General Elections; instead they were considered unsuitable and labelled (by common law) as 'idiots' or 'lunatics.' ${ }^{1}$ Furthermore, the 1949 Act disenfranchised those with mental disorders by refusing to allow patients to register to vote while under the care of psychiatric institutions. This ruling was not revoked until the Electoral Administration Act 2006, 58 years after the advent of 'universal suffrage' in the UK. Currently, patients on psychiatric in-patient units (either informally or detained under civil sections of the Mental Health Act 1983) have a right to register to vote either in person, by post, or by proxy (under the Electoral Administration Act 2006).

I decided to investigate current knowledge of in-patients' voting rights among healthcare workers on two adult in-patient psychiatric wards. I asked 19 staff members whether or not they believe psychiatric in-patients have the right to vote and whether legal status (i.e. informal or detained under Sections 2 or 3 of the Mental Health Act 1983) made any difference to this provision. Those who took part included psychiatric trainees $(n=3)$, registered mental health nurses $(n=9)$ and healthcare assistants $(n=7)$.

Of those I asked, responders were only aware of two in-patients who were registered to vote; these patients were both receiving care informally on a female psychiatric ward. The majority of participants agreed that informal patients did have a right to vote $(n=17,89 \%)$. Interestingly, only $12(63 \%)$ and $10(53 \%)$ people agreed that patients had this right if detained under Sections 2 and 3 of the Mental Health Act 1983 respectively. Almost all who participated stated that they had not been given information regarding voting rights leading up to the election, and that lack of awareness had made it impossible to provide informed decisions in response to my questions. The reasons cited for believing that patients detained under the Mental Health Act 1983 may not have voting rights included increased severity of illness, practical problems getting patients to polling stations, and a belief that current legislation is likely to be discriminatory and out of date. More than half $(n=11,58 \%)$ of those interviewed (including all three psychiatric trainees) reported that this was the first time that they had been asked to consider patients' voting rights.

These findings, albeit from an investigation with clear limitations, demonstrates that knowledge of voting rights is lacking among those working in psychiatric units. I believe this criticism is a reflection of lack of clear guidance, and a deficiency in undergraduate/postgraduate psychiatric training. This is not a new issue - similar concerns raised in previous research appear to have been overlooked. ${ }^{2,3}$

I believe psychiatric in-patients and their interests remain underrepresented by our political system and that lack of clarity in this area is inadequate justification for care providers to take a laissez-faire approach. I am not proposing that healthcare professionals should be encouraging in-patients to vote, but rather that we should be proactive in making them aware that they can vote.

1 Indermaur J. Principles of the Common Law. Richardson, 2009.

2 Smith H, Humphreys M. Changes in laws are necessary to allow patients detained under Mental Health Act to vote. BMJ 1997; 315: 431.

3 Humphreys $M$, Chiswick D. Getting psychiatric patients to the polls in the 1992 General Election. Psychiatr Bull 1993; 17: 18-9.

Gareth Rees, Solihull Hospital, Birmingham and Solihull Mental Health NHS Foundation Trust, UK. Email: garethrees8@doctors.org.uk

doi: 10.1192/bjp.197.2.159 